\title{
Редкоземельные и редкие карбонаты фенитов Косьюского рудного поля (Средний Тиман)
}

\author{
Удоратина О.В. ${ }^{1,2}$, Варламов Д.А. ${ }^{3}$ \\ ${ }^{\prime}$ Институт геологии Коми НЦ УрО РАН, Сыктывкар, udoratina@geo.komisc.ru \\ ${ }^{2}$ Томский государственный университет, Томск \\ ${ }^{3}$ Институт экспериментальной минералогии РАН, Черноголовка
}

Аннотация. Рассмотрены находки редкоземельных и редких (по встречаемости) карбонатов в образцах из рудного редкометалльно-редкоземельного поля Косью (Средний Тиман). Установлено появление редкоземельных (фтор)карбонатов в щелочных метасоматитах, при этом в составе редких земель преобладают цериевые разности $(\mathrm{Ce}>\mathrm{La}>\mathrm{Nd})$. В целом состав редкоземельных карбонатов из метасоматитов близок таковым из карбонатитов рудного поля Косью, однако, смещен в сторону бескальциевых фторкарбонатов. Приведены составы редких карбонатов (бурбанкита, анкилита, норсетита), появление которых в метасоматитах связано с редкоземельными карбонатами.

Ключевые слова: редкоземельные (фтор)карбонаты, бастнезит, бурбанкит, Косью, Средний Тиман.

\section{Rare-earth carbonates of the phenites of the Kosyu ore field (Middle Timan)}

\author{
Udoratina Oxana ${ }^{1,2}$, Varlamov Dmitry ${ }^{3}$ \\ ${ }^{1}$ Institute FRS of Geology Komi SC UB RAS, Syktyvkar, udoratina@geo.komisc.ru \\ ${ }^{2}$ TSU, Tomsk \\ ${ }^{3}$ IEM RAS, Chernogolovka,dima@iem.ac.ru
}

\begin{abstract}
Rare-earth carbonates of the Kosyu ore rare-metal-rare-earth field (Middle Timan) are considered. The development of rare earth carbonates in alkaline metasomatites is shown. It was found that cerium $(\mathrm{Ce}>\mathrm{La}>\mathrm{Nd})$ predominate in the composition of rare earths. In general, the composition of rare earth carbonates is similar to those known in the carbonatites of the Kosyu ore field, however, the composition is biased towards calcium-free fluorocarbonates. Compositions of rare carbonates (burbankite, ankilite, norsetite), the appearance of which in metasomatites is associated with rare earth carbonates, are given.
\end{abstract}

Key words: rare earth carbonates, bastnasite, burbankite, Kosyu, Middle Timan.

\section{Введение}

В пределах южной части Четласского Камня на Среднем Тимане известны редкометалльноредкоземельные проявления Косьюского рудного узла. Редкометалльно-редкоземельная минерализация связана с четласским комплексом включающем в себя ультраосновные породы, связанные с ними карбонатиты, породы жильной серии и фениты. Вмещающими породами являются метатерригенные и метатерригенно-карбонатные отложения позднерифейских четласской и быстринской серий. В породах «рамы», как и в самих дайковых породах, широко проявлены процессы фенитизации, а в пределах рудных полей развиты разнообразные щелочные метасоматиты (фениты, флогопитовые слюдиты, полевошпатовые метасоматиты) и гидротермальные жильные образования с дотаточно обильной акцессорной редкометалльно-редкоземельной минерализацией (Ивенсен, 1964, Костюхин, Степаненко, 1987, Тиманский..., 2009, Недосекова и др., 2011, 2013, 2017, Голубева и др., 2019, Удоратина и др., 2015, 2016, 2021). Щелочные метасоматиты локализованы в тех же тектонических зонах северо-восточного простирания, что и дайковые ультрабазиты пикрит-лампрофировой серии, но в отличие от магматических дайковых пород (проявленных на широкой территории) они появляются только на отдельных локальных участках. Вмещающие осадочно-метаморфические породы (первично песчаники, алевролиты, сланцы и филлиты) преобразованы в фениты, сложенные новообразованным комплексом минералов: эгирин + щелочные амфиболы + микроклин и альбит, часто с карбонатами. По дайковым ультраосновным породам развивались флогопитовые слюдиты 
и полевошпатовые метасоматиты. Флогопитовые слюдиты и наиболее крупные тела карбонатитов распространены в Косьюской зоне разлома в районе массива (раздува дайки пикритов) р.Косью, где особенно интенсивно проявлены процессы формирования карбонатитов и связанных с ними зон приконтактового метасоматоза. Здесь описаны штокверковые зоны гетит-полевошпатовых пород, тесно связаных с процессом карбонатитообразования, наиболее поздние кварц-гетит-гематитовые жилы пересекают все породы массива.

Геологические, петрографо-минералогические и петрогеохимические исследования последних лет по карбонатитам и щелочным пикритам приведены в работах (Недосекова и др., 2013, Голубева и др., 2019, Удоратина и др., 2021), данные по минералогии - в работах (Ковальчук и др., 2013, Недосекова и др., 2017).

В верховьях реки Косью были отобраны щелочные метасоматиты - фениты, развившиеся по песчаникам визингской свиты четласской серии. В них были изучены редкометалльные и редкоземельные акцессорные рудные минералы. Редкометалльная минерализация представлена в основном оксидами - колумбитом, высоко Nb рутилом, ильменитом, редкоземельная - в основном фосфатами: монацитом и ксенотимом нескольких генераций, и различными редкоземельными карбонатами и фторкарбонатами (Varlamov et al., 2017).

Предшественниками исследовались карбонаты собственно карбонатитов штока Косью: кальциты, доломиты, сидериты, анкериты, Ba-Sr-Th содержащие кальциты, бастнезит-(Се), бастнезит(La), паризит, анкилит, Sr редкоземельный карбонат, бурбанкит (Ковальчук и др., 2013, Недосекова и др., 2017).

\section{Методика работ}

Проведены комплексные петрографо-минералогические исследования фенитизированных кварцитопесчаников визингской свиты из опробованных поверхностных горных выработок в пределах рудного поля Косью. Материал для исследований получен при полевых исследованиях 2015-2016 гг. Исследования проведены в ЦКП «Геонаука» и ИЭМ РАН (г. Черноголовка). Исследования выполнялись на электронном микроскопе Tescan Vega 3 LMH с энерго-дисперсионной приставкой Oxford Instrument X-Max 50 mn2 (г. Сыктывкар), а также на электронном сканирующем микроскопе производства фирмы Tescan (Czech Republic, https:/www.tescan.com): Tescan VEGA-II $\mathrm{XMU}$ с энергодисперсионным спектрометром INCA Energy 450 и спектрометром с волновой дисперсией Oxford INCA Wave 700, при ускоряющем напряжении 20 кВ. Ток поглощенных электронов на исследованных образцах - от 150 до 400 рА (в зависимости от микрорельефа, структуры и состава образца). Размер электронного зонда на поверхности образца 157-180 нм (Tescan). Область возбуждения в зависимости от состава образца и геометрии фаз может достигать 5 мкм в диаметре. Съемка микрофотографий осуществлялась главным образом в режиме обратно-рассеянных электронов с вещественным контрастом (BSE - back-scattered electrons), г. Черноголовка.

\section{Результаты работы}

Опробованная серия пород включает неизменные, слабоизмененные и фенитизированные кварцитопесчаники, в которых наблюдаются реликтовые и новообразованные парагенезисы минералов. При развитии процессов фенитизации в кварцитопесчаниках начинают развиваться альбит, микроклин, эгирин и комплекс рудных редкометалльно-редкоземельных минералов.

Среди новообразованных породообразующих минералов были установлены эгирин, щелочные амфиболы, железистые хлориты, фторфлогопиты и их безалюминиевые аналоги. Среди акцессориев; цирконы, фосфаты REE, Al, Ba; редкие карбонаты: бурбанкит ( $\mathrm{Na}, \mathrm{Ca}) 3(\mathrm{Sr}, \mathrm{Ba}, \mathrm{Ce}) 3(\mathrm{CO} 3) 5$, норсетит $\mathrm{BaMg}\left(\mathrm{CO}_{3}\right)_{2}$, анкилит-(Ce), Ba-Mn карбонаты, различные фторкарбонаты REE; обширный спектр ториевой минерализации, высокониобиевые рутилы, цериевые минералы с $\mathrm{Mn}, \mathrm{Fe}, \mathrm{Ba}, \mathrm{Pb}$ (Varlamov et al., 2017). В данной работе рассмотрены редкие карбонаты и редкоземельные фторкарбонаты - как правило, бастнезитовой серии).

Редкоземельные (фтор)карбонаты и карбонаты-( $\mathrm{Sr}, \mathrm{Ba})$ чаще всего наблюдаются в полнопроявленных метасоматитах, альбит-микроклин-эгириновых метасоматитах, эгиринитах. Редкоземель- 

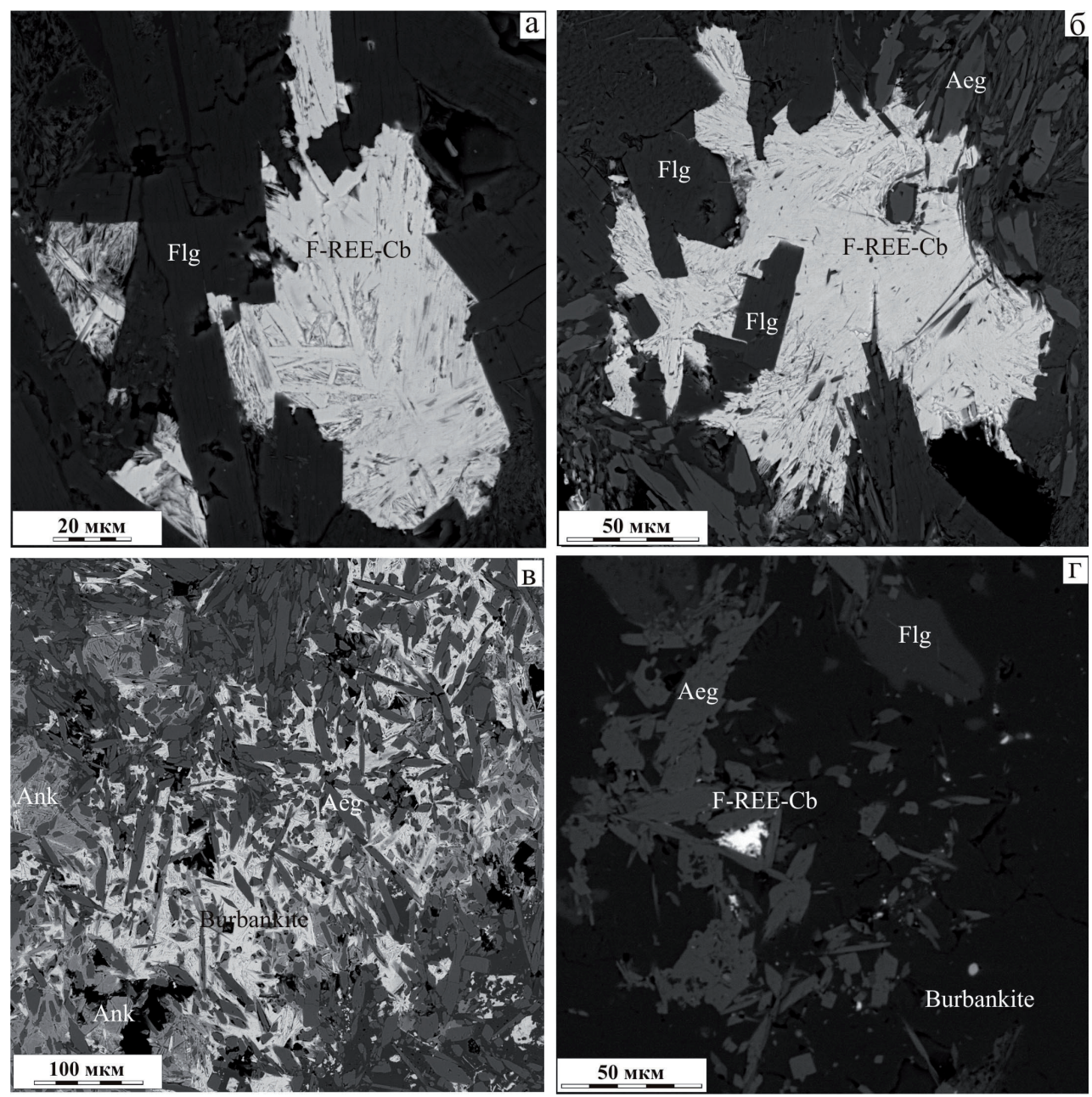

Рис. 1. Распределение агрегатов бастнезита (а-в) и бурбанкита (г) в щелочных метасоматитах по кварцитопесчаникам. Изображения сняты в обратно-рассеянных (BSE) электронах. Flg - флогопит, Ank - aнкерит, Aeg - эгирин, F-REE-Cb - редкоземельные (фтор)карбонаты, Burbankite - бурбанкит.

Fig. 1. Distribution of aggregates of bastnesite (a-c) and burbankite (d) in alkaline metasomatites over quartzite sandstones (BSE image). Flg - flogopite, Ank - ankerite, Aeg - aegerine, F-REE-Cb - редкоземельные (фтор)карбонаты - REE fluorcarbonates, Burbankite - burbankite.

ные (фтор)карбонаты преимущественно бастнезитового состава цементируют совместно с анкеритом эгирин-флогопитовые срастания (рис. 1 a), либо наблюдаются в виде единичных обособлений в породе, но также ассоциируют со слюдой и пироксеном (с флогопитом и эгирином), (рис. 1 б, в). В химическом составе бастнезита содержание оксида кальция обычно не более 5.5 мас. \% (табл. 1), резко преобладают цериевые разности, гораздо реже встречаются лантановые индивиды. Появление лантановых (и La-Nd) разностей связано с процессами окисления церия и сегрегацией Се ${ }^{4+}$ из редкоземельных минералов (как описано в Varlamov et al., 2017). На это же указывают находки собственно цериевых окисных фаз в изученных образцах. Преобладание бастнезита над кальциевыми фторкарбонатами (паризит, синхизит и т.п.) связано с существенно меньшими содержаниями кальция в первичном терригенном субстрате фенитов, т.е. геохимия среды неблагоприятна для формирования кальциевых REE (фтор)карбонатов.

Отдельные мелкие выделения редких карбонатов с малыми содержаниями REE - NaSr карбоната (бурбанкита) и $\mathrm{MgBa}$ карбоната (норсетит) отмечаются как включения в бастнезите или калиевом полевом шпате (рис. 1 г). Кроме того, встречены анкилит-(La) и очень высокостронциевый кальцит (до 20 \% SrO), причем большинство не ассоциирует впрямую с фторкарбонатами. 
Таблица 1. (а) Химический состав (мас. \%) фторкарбонатов редких земель.

Table 1. (a) Chemical composition (wt. \%) of REE fluorcarbonates.

\begin{tabular}{|c|c|c|c|c|c|c|c|c|c|c|c|c|c|c|}
\hline № ח/П & № обр. & $\mathrm{F}$ & $\mathrm{SiO}_{2}$ & $\mathrm{CaO}$ & $\mathrm{FeO}$ & $\mathrm{SrO}$ & $\mathrm{BaO}$ & $\mathrm{La}_{2} \mathrm{O}_{3}$ & $\mathrm{Ce}_{2} \mathrm{O}_{3}$ & $\mathrm{Pr}_{2} \mathrm{O}_{3}$ & $\mathrm{Nd}_{2} \mathrm{O}_{3}$ & $\mathrm{Sm}_{2} \mathrm{O}_{3}$ & $\mathrm{ThO}_{2}$ & Сумма \\
\hline 1 & $341 / 2(14)$ & 4.52 & 0.86 & 2.55 & 1.61 & 1.89 & 0.32 & 14.67 & 32.16 & 2.47 & 12.56 & 1.68 & 1.04 & 76.31 \\
\hline 2 & $341 / 2(22)$ & 2.64 & - & - & - & 0.33 & 0.34 & 18.48 & 34.17 & 2.71 & 12.28 & - & - & 70.95 \\
\hline 3 & $341 / 2(25)$ & 3.74 & 1.07 & 5.74 & 0.54 & 0.69 & 0.53 & 16.91 & 31.00 & 3.01 & 11.07 & 1.00 & 0.68 & 75.98 \\
\hline 4 & $341 / 2(26)$ & 4.48 & 1.24 & 5.11 & 5.63 & 1.08 & - & 14.91 & 28.64 & 2.44 & 9.73 & 1.77 & - & 75.02 \\
\hline 5 & $341 / 2(2.2)$ & 4.30 & 1.20 & 7.10 & 3.90 & 1.52 & - & 12.90 & 26.10 & 2.60 & 8.75 & 1.10 & 1.50 & 70.97 \\
\hline 6 & $341 / 2(7.1)$ & 3.63 & 6.60 & 0.40 & - & - & - & 16.30 & 31.40 & 2.80 & 10.58 & - & - & 71.71 \\
\hline 7 & $340 / 4(2.1)$ & 3.74 & - & 0.60 & 0.40 & - & - & 26.20 & 32.90 & 1.90 & 5.25 & - & - & 70.99 \\
\hline 8 & $340 / 4(5.1)$ & 3.15 & - & 0.70 & - & - & - & 26.60 & 33.10 & 2.20 & 5.74 & - & - & 71.49 \\
\hline 9 & $340 / 4(7.1)$ & 5.23 & - & 0.80 & 0.80 & - & - & 27.70 & 32.00 & 1.70 & 4.96 & - & - & 73.19 \\
\hline 10 & $340 / 4(7.2)$ & 4.64 & - & 2.10 & 2.80 & - & - & 26.30 & 30.50 & 1.30 & 4.79 & - & - & 72.43 \\
\hline 11 & $340 / 4(8.1)$ & 5.55 & - & 0.80 & 0.80 & - & - & 26.70 & 32.70 & 2.10 & 5.41 & - & - & 74.06 \\
\hline 12 & $340 / 4(8.2)$ & 4.78 & - & 1.70 & 1.20 & - & - & 27.10 & 32.00 & 2.00 & 4.79 & - & - & 73.57 \\
\hline 13 & $340 / 4(9.1)$ & 5.10 & - & 1.30 & 1.00 & - & - & 28.20 & 30.50 & 1.40 & 4.87 & - & - & 72.37 \\
\hline 14 & $341 / 2(39)$ & 3.65 & 3.30 & 3.64 & 0.23 & 2.62 & 0.02 & 27.17 & 5.99 & 5.12 & 21.81 & 1.19 & 0.75 & 75.51 \\
\hline 15 & $341 / 2(27)$ & 2.73 & 3.94 & 12.42 & 2.39 & 0.47 & 0.00 & 11.96 & 25.02 & 2.61 & 9.41 & 0.95 & 1.57 & 73.47 \\
\hline 16 & $341 / 2(16)$ & 2.93 & 3.59 & 13.33 & 3.70 & 0.43 & 0.00 & 12.18 & 23.00 & 3.78 & 9.18 & 1.32 & 1.08 & 74.52 \\
\hline
\end{tabular}

Примечание. 1-13 - бастнезит-(Ce), 14 - бастнезит-(La-Nd), 15-16 - паризит-(Ce); 2. Примесь $\mathrm{SiO}_{2}$ обусловлена наличием большого количества субмикронных включений кварца или влиянием матрицы (для малых индивидов), заниженное содержание фтора, вероятно, связано с замещением гидроксил-ионом.

(б) химический состав (оксиды, мас.\%) редких видов бесфтористых карбонатов.

(b) Chemical composition (wt \%) of another fluor-free rare carbonates.

\begin{tabular}{|c|c|c|c|c|c|c|c|c|c|c|c|c|c|}
\hline$№$ п/п & № обр. & $\mathrm{Na}_{2} \mathrm{O}$ & $\mathrm{SiO}_{2}$ & $\mathrm{MgO}$ & $\mathrm{CaO}$ & $\mathrm{SrO}$ & $\mathrm{BaO}$ & $\mathrm{La}_{2} \mathrm{O}_{3}$ & $\mathrm{Ce}_{2} \mathrm{O}_{3}$ & $\mathrm{Pr}_{2} \mathrm{O}_{3}$ & $\mathrm{Nd}_{2} \mathrm{O}_{3}$ & $\mathrm{ThO}_{2}$ & Сумма \\
\hline 1 & $341 / 2(23)$ & 7.93 & 9.81 & - & 8.38 & 17.08 & 15.41 & 2.95 & 6.03 & 0.51 & 2.43 & - & 70.53 \\
\hline 2 & $341 / 2(2.1)$ & 11.43 & 4.40 & - & 4.05 & 21.19 & 7.79 & 4.76 & 8.50 & - & 2.59 & 0.55 & 65.21 \\
\hline 3 & $341 / 2(41)$ & 3.73 & 8.50 & - & 10.42 & 17.36 & 0.20 & 15.54 & 7.28 & 2.20 & 7.67 & 0.20 & 73.10 \\
\hline 4 & $340 / 2(13)$ & 0.28 & 1.39 & 13.21 & 0.44 & 0.37 & 51.11 & 0.45 & 0.68 & 0.12 & 0.27 & - & 68.13 \\
\hline 5 & $341 / 2(40)$ & - & 1.23 & - & 40.94 & 17.91 & 0.43 & 0.28 & 0.83 & - & 0.60 & - & 64.06 \\
\hline
\end{tabular}

Примечание. 1. Приведены данные микрозондового анализа (без учета $\mathrm{CO}_{3}$ ); Минералы: 1, 2 - бурбанкит, 3 - анкилит-(La), 4 - норсетит, 5 - высокостронциевый кальцит.

\section{Выводы}

В фенитах, сопровождающих карбонатитовые комплексы в рудном поле Косью, на фоне образования щелочной минеральной ассоциации $(\mathrm{Ab}+\mathrm{Kfs}+\mathrm{Aeg}+\mathrm{Chl}+\mathrm{Phl})$ наблюдается развитие достаточно обильной рудной минерализации на базе редкометалльно-редкоземельных минералов.

В данной работе рассмотрены редкоземельные фторкарбонаты и редкие бесфтористые карбонаты. Среди них резко преобладают низко- и бескальциевые фторкарбонаты бастнезитовой серии (бастнезит-(Ce), редко бастнезит-(La)) с подчиненным количеством паризита, также встречаются находки редких карбонатов типа бурбанкита, анкилита, норсетита. Редкоземельные (фтор) карбонаты и карбонаты-(Sr-Ba) чаще всего наблюдаются в полнопроявленных метасоматитах, альбит-микроклин-эгириновых метасоматитах, эгиринитах. 


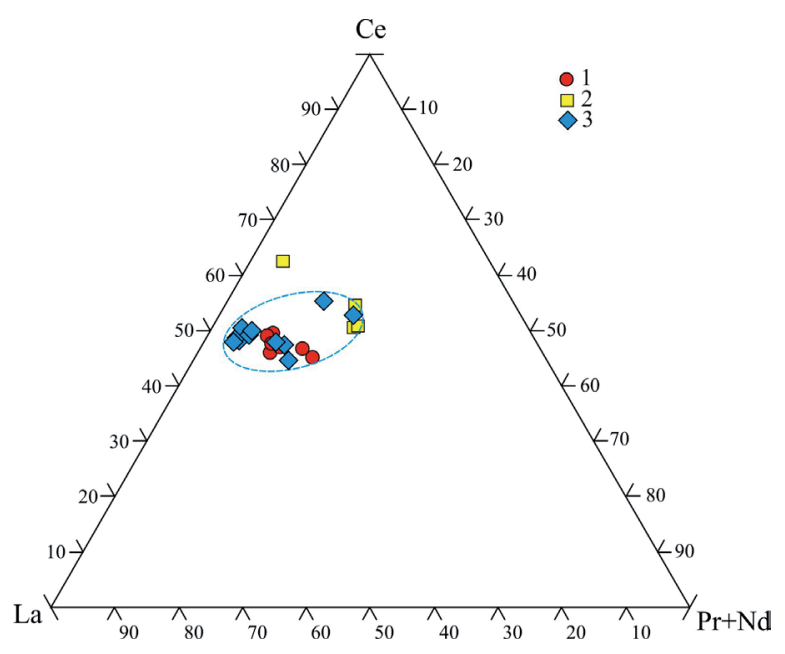

Преобладание бастнезитовой серии обусловлено низким геохимическим фоном кальция в исходных метатерригенных вмещающих породах. Фторкарбонаты REE и редкие Sr-Ba содержащие карбонаты, вероятно, разнесены по времени минералообразования, поскольку фтор, как правило, отсутствует в $\mathrm{Sr}-\mathrm{Ba}$ разностях. Это отличает описанную REE-карбонатную минерализацию от такой же, приуроченной непосредственно к карбонатитам. Появление существенно лантановых минералов связано, скорее всего, с окислением церия до $\mathrm{Ce}^{4+}$ и его сегрегацией.

Работа выполняется при финансовой поддержке РФФИ и Республики Коми в рамках научного проекта № 20-45-110010.

\section{Литература}

1. Варламов Д.А., Удоратина О.В. Минералы редкометалльно-редкоземельных рудных полей Четласского Камня Среднего Тимана // Геология и минеральные ресурсы Европейского северо-востока России. Материалы XVII Геологического съезда Республики Коми. Сыктывкар. 2019. С.160-162.

2. Голубева И.И., Ремизов Д.Н., Бурцев И.Н., Филиппов В.Н., Шуйский А.С. Флюидизатно-эксплозивные ультрамафиты дайкового комплекса Среднего Тимана и их парагенетическая связь с карбонатитами // Региональная геология и металлогения. 2019. С. 1-13.

3. Ивенсен Ю.П. Магматизм Тимана и полуострова Канин. М.-Л. Изд-во: Наука. 1964. 126 с.

4. Ковальчук Н.С., Шумилова Т.Г., Степаненко В.И. Редкоземельная минерализация в карбонатитах Косьюского массива (Средний Тиман) // Записки РМО. 2013. Т. 142. № 3. С. 109-132.

5. Костюхин М.Н., Степаненко В.И. Байкальский магматизм Канино-Тиманского региона. Л. Изд-во: Наука. $1987.232 \mathrm{c.}$

6. Недосекова И.Л., Владыкин Н.В., Удоратина О.В., Ронкин Ю.Л. Карбонатиты четласского комплекса (Средний Тиман): геохимические и изотопные данные // ЕЖЕГОДНИК-2012. Труды ИГГ УрО РАН. Вып. 160. 2013. С. 150-158.

7. Недосекова И.Л., Замятин Д.В., Удоратина О.В. Рудная специализация карбонатитовых комплексов Урала и Тимана // Литосфера. 2017. № 2. С. 60-77.

8. Недосекова И.Л., Удоратина О.В., Владыкин Н.В., Прибавкин С.В, Гуляева Т.Я. Петрохимия и геохимия дайковых ультрабазитов и карбонатитов Четласского комплекса (Средний Тиман) // ЕЖЕГОДНИК-2010. Тр. ИГГ УрО РАН. Вып. 158. 2011. С. 122-130.

9. Тиманский кряж. Т. 2. Литология и стратиграфия,геофизическая характеристика земной коры, тектоника, минерально-сырьевые ресурсы (ред. Л.П. Шилов, А.М. Плякин, В.И. Алексеев). Ухта. Изд-во: УГТУ. 2009. $460 \mathrm{c}$.

10. У Уоратина О.В., Вирюс А.А., Козырева И.В, Швецова И.В., Капитанова В.А. Возраст монацитов жильной серии четласского комплекса (Средний Тиман): Th-U-Pb данные // Вестник Института геологии Коми НЦ УрО РАН. Сыктывкар. 2015. № 3. С. 23-29.

11. Удоратина О.В., Капитанова В.А. Редкометалльно-редкоземельные месторождения и рудопроявления севера Урала и Тимана: геохронология рудного процесса // Известия Коми НЦ УрО РАН. 2016. № 4(28). C. 86-101.

12. Удоратина О.В., Шмакова А.М., Варламов Д.А., Шуйский А.С. Ультраосновные породы Новобобровского рудного поля (Средний Тиман): минералогия, петрография, петрогеохимия // Известия Коми научного центра УрО РАН. Сер. «Наука о Земле». Сыктывкар. 2021. (в печати).

13. Varlamov D.A., Udoratina O.V., Burakov N.N. Unusual monazites and Ce segregation process during alkaline metasomatosis of acid substrates (Kosyu ore field, Middle Timan) / Magmatism of the Earth and related strategic metal deposits. XXXIII International conference. Abstract. Miass. 2017. P. 292-295. 